\title{
Experiencia en Plastinación con Resina Poliéster P-4 para Cortes Anatómicos
}

\author{
Plastination Experience in Polyester Resin (P-4)
}

\author{
Marcos Valenzuela O.; Camila Azocar S.; Krystel Werner F. ; Eduardo Vega P. \& Fabio Valdés G.
}

\begin{abstract}
VALENZUELA, O. M.; AZOCAR, S. C.; WERNER, F. K.; VEGA, P. E. \& VALDÉS, G. F. Experiencia en plastinación con resina poliéster P-4 para cortes anatómicos. Int. J. Morphol., 30(3):810-813, 2012.

RESUMEN: El Laboratorio de Plastinación de la Universidad de los Andes ha trabajado hasta hoy, exclusivamente la técnica en Silicona para preservar el material cadavérico mediante este tipo de conservación. Sin embargo, este método tiene algunas desventajas en cortes anatómicos finos. Se desarrolló un método de plastinación en resina poliéster, en base a la técnica ya protocolizada, adaptándolas a nuestro laboratorio, con el fin de obtener muestras con mayor resistencia y calidad, sin alterar las estructuras. Se utilizaron cortes anatómicos de segmentos distales de miembro inferior humano fijados en acetona a $-17^{\circ} \mathrm{C}$ y otros de encéfalo de vacuno fijados con formalina acuosa al $10 \%$ a $4^{\circ} \mathrm{C}$, de un grosor que varía entre 0,4 y $0,8 \mathrm{~cm}$. Se procedió a deshidratar las muestras en acetona a $-17^{\circ} \mathrm{C}$ para luego seleccionar piezas que fueron impregnadas y plastinadas con resina P-4 sin catalizador y otras con catalizador en proporciones 2:1. El proceso de polimerización fue común para ambas con luz ultravioleta. Se obtienen muestras sólidas y rígidas, con cierta transparencia, especialmente en los cortes más finos. No se observaron alteraciones de forma y tamaño. Los mejores resultados en cuanto a transparencia, se obtuvieron con la Resina sin catalizador. Se logró estandarizar una técnica con Resina poliéster P-4, obteniendo cortes anatómicos de buena calidad y con una resistencia mucho mayor que la obtenida para este tipo de muestras en la plastinación con Silicona.
\end{abstract}

PALABRAS CLAVE: Preservación de tejidos; Plastinación; Resinas.

\section{INTRODUCCIÓN}

Desde el año 2002 que la Unidad de Anatomía Normal de la Universidad de los Andes comenzó a desarrollar la técnica de Plastinación, pero por años estaba destinado exclusivamente a plastinar muestras en silicona, muy efectiva en piezas completas disecadas (Jimenez \& Isaza, 2005; Von Hagens et al., 1987; Latorre et al., 2007; Suazo \& Roa, 2008). Al utilizar la técnica con siliconas en cortes delgados las muestras quedaban muy frágiles para utilizarse en docencia.

El objetivo de este estudio fue desarrollar un método de Plastinación en resina poliéster adaptando las técnicas ya protocolizadas y publicadas (Latorre \& Henry, 2007) a nuestra realidad, con el fin de obtener muestras con una mayor resistencia y calidad, sin alterar las estructuras.

\section{MATERIAL Y MÉTODO}

Se utilizan muestras anatómicas humanas y de animales divididas en tres grupos (A, B y C) con procedimientos similares pero en distintos períodos para cada uno de ellos. Correspondiendo al grupo A, 12 cortes sagitales y parasagitales de miembro inferior de un grosor de $0,4 \mathrm{~cm}$ fijados con acetona al $96 \%$ a $-20^{\circ} \mathrm{C}$ durante 30 días; el grupo B correspondiente a 25 cortes coronales y horizontales de encéfalos de vacuno de un grosor promedio de $0,6 \mathrm{~cm}$ fijados con formalina acuosa al $10 \%$, durante 30 días tiñendo sustancia gris en algunos de ellos con el método de Barnard, Robert y Brown (Bravo, 2006) previo a la plastinación y el grupo $\mathrm{C}$, correspondiente a 12 cortes transversales (tipo medallón) de miembro inferior humano de un grosor promedio de $0,4 \mathrm{~cm}$ que fueron fijados con acetona de $95 \%$ a $-20^{\circ} \mathrm{C}$ por 30 días.

La deshidratación de todas las muestras se hizo con acetona de $97 \%$ y $100 \%$ en forma ascendente a $-20^{\circ} \mathrm{C} \mathrm{du}$ rando un promedio de 25 días, y controlando el grado de deshidratación mediante un Acetonómetro, hasta comprobar un porcentaje de agua en los tejidos inferior al 2\% (Valdes et al., 2010). Las muestras totalmente deshidratadas, son sacadas de la acetona y trasladan a una cámara de $4^{\circ} \mathrm{C}$ por un par de horas y luego a temperatura ambiente. 
Dentro de la cámara de vacío, a temperatura ambiente, del grupo A, 8 cortes se sumergen en resina poliéster sin catalizador y 4 en resina con catalizador $(1 \mathrm{~g}$ de catalizador (peróxido de metiletilcetona] por cada $100 \mathrm{~g}$ de resina). En la totalidad de las muestras de los grupos B y C, el proceso se hace con resina sin catalizador.

Se dejan las muestras sumergidas durante 24 horas en la resina. Transcurrido este tiempo, se sella la cámara y comienza el vacío iniciando con una presión de $50 \mathrm{~mm} \mathrm{Hg}$ hasta terminar en $10 \mathrm{~mm} \mathrm{Hg}$ con un promedio de 72 horas continuas (el tiempo de impregnación forzada es medido o determinado en base a la disminución de burbujas que salen al producirse el vacío). Esta presión es regulada y controlada mediante un Vacuómetro de Bennett (Valdes et al.; Henry \& Latorre, 2007). Durante todo el proceso de impregnación, la cámara se mantiene cubierta con paños oscuros sin permitir el paso de la luz. Una vez que las burbujas se dejan de producir, se detiene la bomba de vacío y se dejan las muestras en reposo dentro de la misma cámara por 12 horas continuas, dejando que el vació se pierda lentamente. Transcurrido este tiempo se abre la cámara. Paralelo a este procedimiento se arman las cámaras de vidrio para incluir los cortes y proceder a la etapa de polimerización con luz UV.
Para el armado de estas, se utilizan dos placas de vidrio de $25 \times 15 \mathrm{~cm}$. Entre estas placas a unos dos centímetros del borde, se coloca un tubo de silicona de $5 \times 8 \mathrm{~mm}$ de diámetros y $80 \mathrm{~cm}$ de largo que lo recorre en todo su perímetro. Estos vidrios se unen con doble clips (dos en promedio por cada lado) dejando solamente uno de los lados de la cámara abierto para introducir la resina y las muestras. Se llenan un tercio de ella con el mismo tipo de resinas en que fueron incluidas, se colocan las muestras (tres por cada cámara promedio) previniendo que no se topen entre si ni con los bordes y se termina de rellenar con resina. Se unen los tubos de silicona entrecruzándolos y evitando que queden espacios con aire y burbujas al interior. Se colocan los clips faltantes y el borde de la unión de los tubos, se pega con silicona de sellado para evitar que la resina líquida discurra hacia fuera. Se deja reposar hasta que la silicona haya sellado totalmente (Fig. 1). A continuación se colocan las cámaras de vidrio en la luz UV. El proceso de polimerización se efectuó durante el día con exposiciones a la UV de 1 hora seguida de intervalos de 30 minutos sin UV entre cada etapa. Las muestras fueron expuestas a la luz UV durante 15 horas promedio, se coloca un ventilador que funciona en paralelo con la UV para evitar el daño de la reacción exotérmica de este proceso. Transcurrido este tiempo, se retiran los clips y el tubo de silicona, se dejan las cámaras

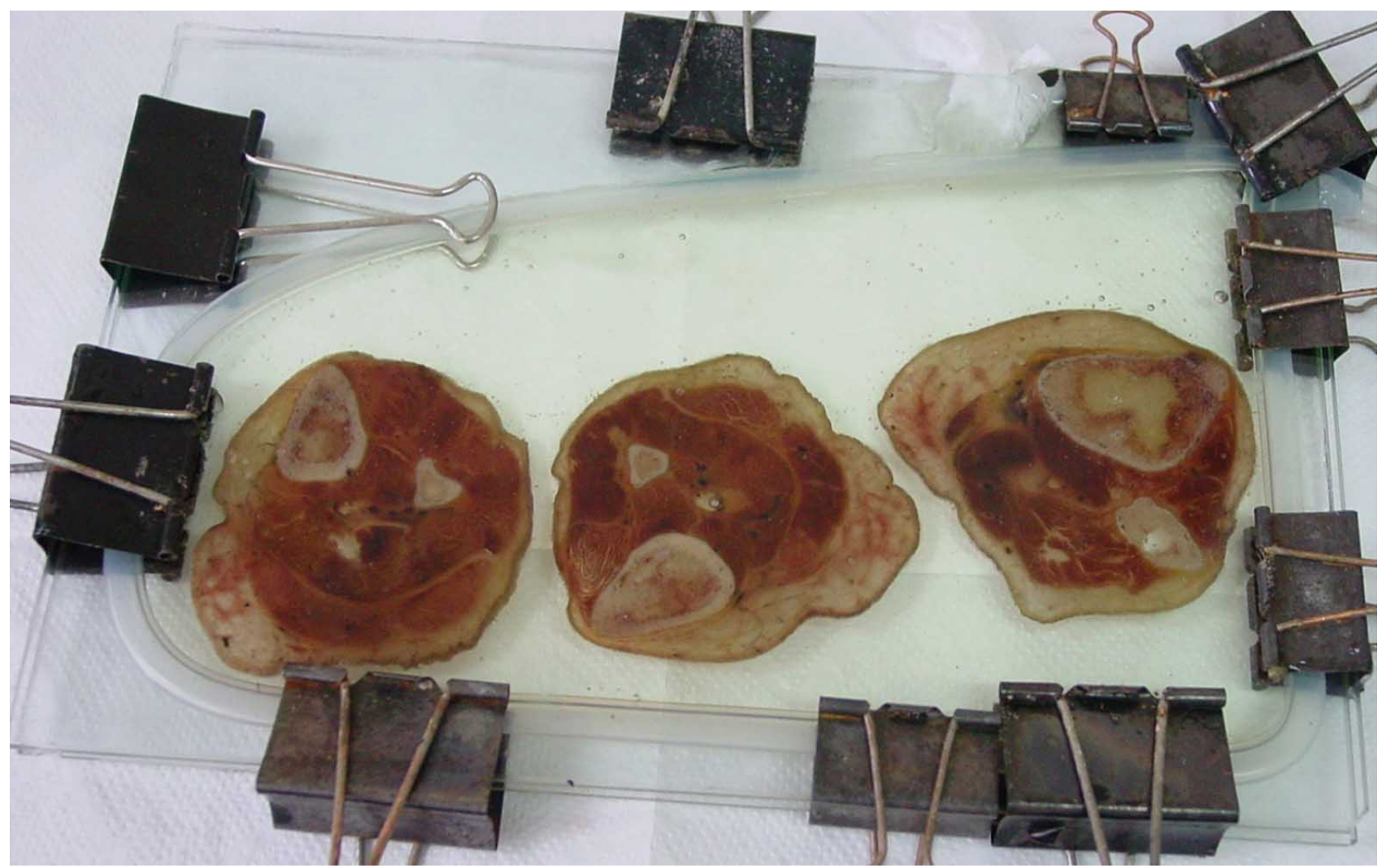

Fig. 1. Placas de vidrio selladas en todo su perímetro con silicona, unidas con las muestras y sujetadas con doble clips. 
en forma vertical por un par de horas, esto permite que los vidrios se desprendan más fácilmente. Luego de desprender las muestras de los vidrios, se envuelven con un plástico transparente tipo Europlas y se dejan sobre una superficie plana para evitar bandeo (curvamiento) y luego se cubren con bolsas o paños oscuros para no permitir el paso de la luz e impedir que se oscurezcan.

Transcurridos 7 días se procede a recortar con una sierra la resina sobrante y se guardan las muestras en cajas plásticas listas para su uso.

\section{RESULTADOS}

Se obtuvieron muestras sólidas y rígidas con cierta transparencia especialmente en los cortes sagitales de pie y particularmente en las piezas que fueron procesadas con la resina sin catalizador. No se observan alteraciones de forma ni tamaño. El desprendimiento de las placas de vidrio no presento dificultad con una excepción donde se aplicó demasiada silicona sellante y fue necesario romper uno de los vidrios. Los cortes de encéfalo teñidos no vieron alterada su coloración durante el proceso.

Se logró estandarizar una técnica de plastinación con Resina poliéster P-4.

\section{DISCUSIÓN}

Con esta técnica, se logró obtener cortes anatómicos de muy buena calidad sin alteración en la morfología de las estructuras y con una resistencia mucho mayor que la obtenida para este tipo de muestras en la plastinación con Silicona (Fig. 2).

El cambio graduado en ascenso de temperatura que se hace al sacar las muestras de la acetona es con el fin de evitar una mayor retracción de los tejidos por un aumento brusco de esta (Valdes et al.). Todo el proceso de impregnación y polimerización se hace cubriendo las cámaras con paños oscuros para evitar el oscurecimiento de las muestras (Henry \& Latorre; Latorre \& Henry).

En el proceso de polimerización con luz UV, se produce un sobrecalentamiento de las muestras por efecto de la exotérmica que produce la resina al polimerizar lo que puede producir daño a las muestras (quemaduras de los tejidos, quebrajamiento de la resina) por lo cual se utiliza un ventilador de aire frio que funciona paralelamente con la luz UV, para disminuir la temperatura (Henry \& Latorre; Latorre \& Henry). Durante los procesos con resina, se recomienda trabajar en lugares ventilados ya que esta produce gases tóxicos que son dañinos para la salud.

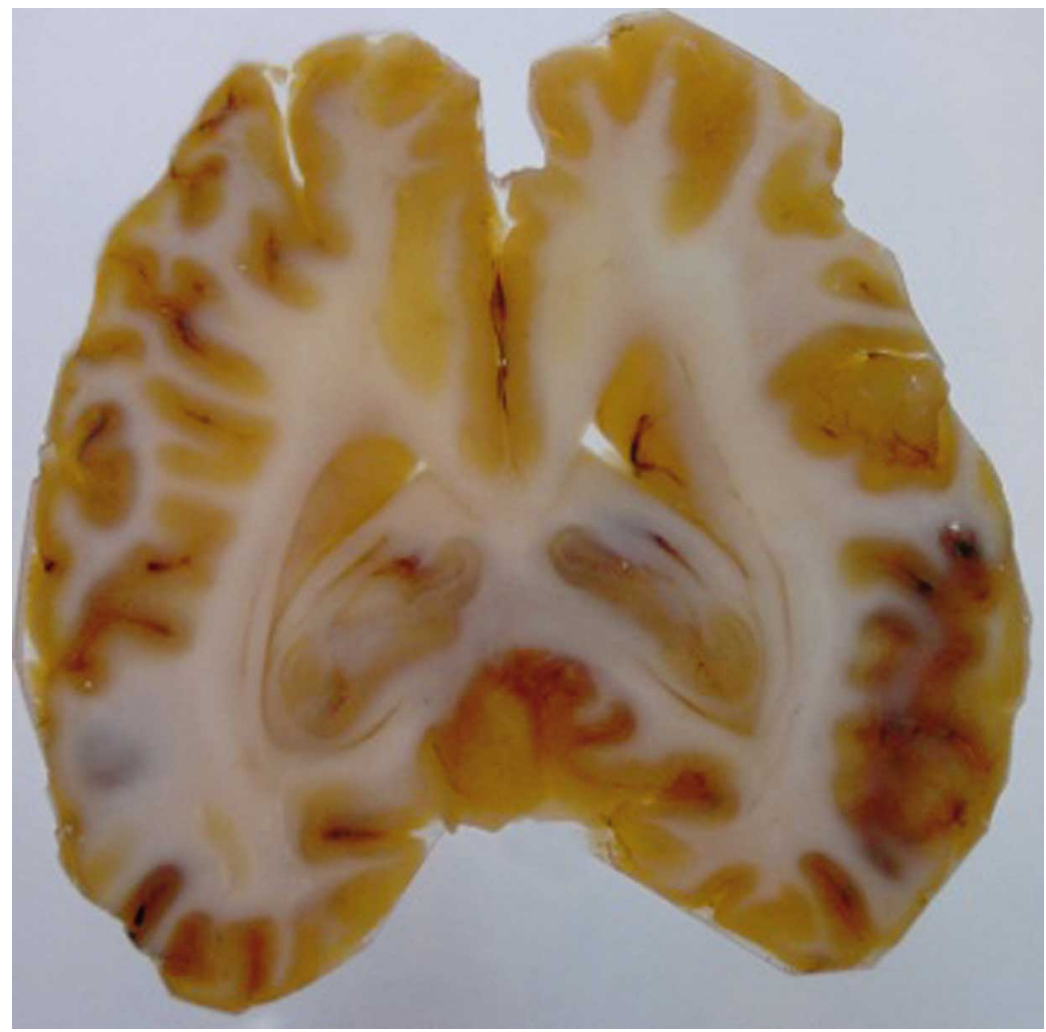

Fig. 2. Corte anatómico de encéfalo plastinado con resina poliéster $\mathrm{p}-4$. 
El interior de las cámaras de vidrio debe ser unos 2 $\mathrm{mm}$ más alto que el grosor de los cortes, para que estas muestras entren fácilmente en su interior, las que además se deben colocar con sumo cuidado para evitar que se produzcan burbujas en el interior de las muestras (Bravo) al entrar con mucha presión.

No es conveniente aplicar demasiada silicona de sellado al unir los tubos de silicona, pues nos dimos cuenta que este exceso dificulta luego el desprendimiento de las placas de vidrio lo cual eventualmente podría dañar las muestras.
Si bien con ambos tipos de resina (con y sin catalizador) los resultados son óptimos y bastante similares en cuanto a transparencia y rigidez, se recomienda la resina pura ya que al no tener aditivos, resulta más fácil su manejo. Durante la polimerización hay una menor exotérmia lo que disminuye la temperatura del proceso bajando las posibilidades de que la pieza se queme por el calor. Y además la resina sin catalizador utilizada en la impregnación es reutilizable lo que a la larga se puede ver reflejado en los costos del procedimiento.

VALENZUELA, O. M.; AZOCAR, S. C.; WERNER, F. K.; VEGA, P. E. \& VALDÉS, G. F. Plastination experience in polyester resin (P-4). Int. J. Morphol., 30(3):810-813, 2012.

SUMMARY: The plastination laboratory at Universidad de los Andes has always worked exclusively silicone as a technique to preserve cadaveric material. However, this method has disadvantages in thin anatomical pieces. A plastination method has been developed using polyester resin P-4, using an already protocolized technique and adapting it to our laboratory to obtain better quality and resistant pieces, without altering the anatomical structures. Anatomical pieces of human lower extremities were used, which were fixated in acetone at $-17^{\circ} \mathrm{C}$ and bovine encephalous pieces, fixated with $10 \%$ aquoeus formalyn at $4^{\circ} \mathrm{C}$, with a variable width of 0.4 to $0.8 \mathrm{~cm}$. The pieces were then dehydrated in acetone at $-17^{\circ} \mathrm{C}$; among these pieces, some were selected, impregnated and plastinated with P-4 resin, using in some of them a catalyst in a ratio of 2:1. The polymerization process was the same for all pieces with ultraviolet light. Solid and rigid pieces were obtained, with a partial transparency, especially on the thinnest cuts. No alterations in size and shape were observed. The best results in transparency were obtained with the technique without the use of catalyst. An adapted standardized protocol for polyester resin P-4 technique was achieved, obtaining good quality anatomical pieces with a higher resistance compared to pieces plastinated using the silicone technique.

KEY WORDS: Tissue preservation; Plastination; Resin.

\section{REFERENCIAS BIBLIOGRÁFICAS}

Bravo, H. Plastinación, una Herramienta Adicional para la Enseñanza de la Anatomía. Int. J. Morphol., 24(3):475-80, 2006.

Henry, R. W. \& Latorre, R. Polyester Plastination of Biological Tissue: P40 Technique for Brain Slices. J. Int. Soc. Plastination, 22:59-68, 2007.

Jimenez, R. \& Isaza, O. Plastination: a modern anatomical technique. Iatreia, 18(1):99-106, 2005.

Latorre, R. \& Henry, R. W. Polyester Plastination of Biological Tissue: P40 Technique for Body Slices. J. Int. Soc. Plastination, 22:69-77, 2007.

Latorre, R. M.; García-Sanz, M. P.; Moreno, M.; Hernández,.; Gil, F.; López, O.; Ayala, M. D.; Ramírez, G.;Vázquez, J. M.; Arencibia, A. \& Henry, R. W. How useful is plastination in learning anatomy?. J. Vet. Med. Educ.,34(2):172-6, 2007.

Suazo, G. I. \& Roa, I. Anatomía microscópica de las glándulas salivales por medio de una técnica histológica convencional y no convencional. Int. J. Morphol., 26(3):689-695, 2008.
Valdes, F.; Vega, E. \& Valenzuela, M. Estudio comparativo de dos técnicas de plastinación. Int. J. Morphol., 28(3):783-6, 2010.

Von Hagens, G.; Tiedemann, K. \& Kriz W. The current potential of plastination. Anat. Embryol., 175:411-21, 1987.

Dirección para correspondencia:

Dr. Fabio Valdés $\mathrm{G}$.

Avda. San Carlos de Apoquindo 2200

Santiago

CHILE

Tel: 56(2)4129307

Email: fvaldes@miuandes.cl

Recibido : 09-06-2012

Aceptado: 11-07-2012 